\title{
VIGOR DE SEMENTES DE RABANETE E DESEMPENHO DE PLANTAS EM CAMPO ${ }^{1}$
}

\author{
JULIO MARCOS FILHO²,ANALÚCIAPEREIRAKIKUTT ${ }^{3}$
}

\begin{abstract}
RESUMO - As relações entre os resultados de testes de germinação e de vigor, obtidos em laboratório, com a emergência de plântulas em campo têm sido bem documentadas na literatura. No entanto, essa situação não se verifica quanto às informações sobre os efeitos do vigor das sementes sobre o desenvolvimento e produção das plantas. Esta pesquisa procurou avaliar a influência do vigor de diferentes lotes de sementes de rabanete, cultivares Gigante Siculo e Cometa, sobre o comportamento das plantas em campo. Primeiramente, o potencial fisiológico das sementes foi avaliado mediante a condução de testes de germinação (velocidade e porcentagem), envelhecimento acelerado com solução saturada de $\mathrm{NaCl}$, deterioração controlada, condutividade elétrica e emergência de plântulas. $\mathrm{O}$ experimento de campo foi instalado mediante a semeadura direta, ajustando-se o estande inicial para 20 plantas por metro linear, com base na porcentagem de germinação de cada lote. As práticas culturais foram efetuadas de acordo com as recomendações para a cultura do rabanete. A emergência de plântulas foi determinada aos 11 dias após a semeadura; nesta época e aos 18, 23 e 30 dias avaliaram-se a altura, o número de folhas e a massa da matéria seca da raiz e da parte aérea. A colheita foi efetuada aos 30 dias, avaliando-se a produção de raízes $\left(\right.$ t.ha $\left.{ }^{-1}\right)$. Os resultados obtidos para ambas as cultivares permitiram concluir que o vigor das sementes pode se relacionar com o desenvolvimento inicial das plantas, mas os efeitos não se manifestam sobre a produção final.
\end{abstract}

Termos para indexação: Raphanus sativus, hortaliça, potencial fisiológico, produção.

\section{RADISH SEED VIGORAND PLANT FIELD PERFORMANCE}

ABSTRACT - The relationship of laboratory seed germination and vigour to seedling emergence and stand establishment is well documented in the literature. However, there is less information relating these effects to plant development and yield. The aim of this research was to evaluate whether differences in radish seed vigour would affect crop performance. Four seed lots of 'Gigante Siculo' and three of 'Cometa' were subjected to germination (speed and percentage), saturated salt accelerated aging, controlled deterioration, electrical conductivity, and seedling emergence tests to identify possible differences in seed physiological potential. A field experiment was performed by direct sowing and effects of seed physiological potential were overcome by adjusting seed rates according to germination percentage of each lot, to obtain a stand of 20plants. $\mathrm{m}^{-1}$ in a row spacing of $0,20 \mathrm{~m}$. The practices of land preparation, fertilizer application, irrigation and weed control were standard for radish culture. Seedling emergence count was made 11 days after sowing, and plant height, plant dry weight and number of leaves/plant were determined at 11, 18, 23, and 30 days after sowing. At harvest (30 days after sowing), seed lots were rated for root yield (t.ha ${ }^{-1}$ ). 'Gigante Siculo' plant development during the first 18 days as measured by plant height and dry matter accumulation was affected by seed vigour. This effect was also detected in 'Cometa' during plant vegetative growth, but was not sufficient to influence root yield.

Index terms: Raphanus sativus, vegetable, physiological potential, yield.

\footnotetext{
${ }^{1}$ Submetido em 07/06/06. Aceito para publicação em 07/08/2006;

${ }^{2}$ Eng. Agrônomo, Dr., Professor Titular do Departamento de Produção Vegetal, USP/ESALQ. Caixa Postal 9, CEP: 13418-900, Piracicaba/SP,
}

\footnotetext{
jmarcos@esalq.usp.br; Bolsista do CNPq.

${ }^{3}$ Doutoranda em Fitotecnia, Departamento de Produção Vegetal, USP/ ESALQ. Bolsista FAPESP, alkikuti@esalq.usp.br.
} 


\section{INTRODUÇÃO}

O rabanete é uma espécie cultivada principalmente em propriedades relativamente pequenas em cinturões verdes, em áreas com acentuada diversidade no cultivo de hortaliças. Apresenta ciclo curto, aspecto interessante para a composição de sistemas de produção com espécies mais tardias, permitindo o planejamento de aproveitamento racional do terreno. Tratase de uma espécie importante, sob o ponto de vista econômico, mas pouco contemplada pela pesquisa, principalmente na área de sementes.

Essa situação não é exclusiva para as sementes de rabanete. Embora a pesquisa com sementes de hortaliças venha apresentando evolução significativa no Brasil a partir dos anos 1990, os trabalhos são menos freqüentes que os conduzidos com espécies de grandes culturas. É verdade que são cultivadas numerosas espécies olerícolas, cada qual com os respectivos problemas, mas o volume de conhecimento disponível não é condizente com a importância do assunto.

De modo geral, a literatura documenta a relação entre a germinação e o vigor, avaliados em laboratório, e a emergência das plântulas em campo. Sabe-se, por exemplo, que sob condições ambientais adequadas após a semeadura, os resultados de germinação se aproximam da porcentagem de emergência, mas a avaliação do vigor é necessária para estimar o potencial de desempenho das sementes quando as condições de ambiente se desviam das mais adequadas.

No entanto, a disponibilidade de informações para a avaliação do vigor de sementes de rabanete é restrita. O exame da literatura indica que Delouche e Baskin (1973) destacaram a eficiência do teste de envelhecimento acelerado a $42^{\circ} \mathrm{C}$ durante 48h, enquanto Hampton e TeKrony (1995) recomendaram a combinação $45^{\circ} \mathrm{C}$ durante $48 \mathrm{~h}$. Além dessas referências, Carpi (2005) enfatizou que o teste de envelhecimento acelerado $\left(41^{\circ} \mathrm{C} / 48 \mathrm{~h}\right)$ foi sensível para detectar diferenças no potencial fisiológico de sementes de rabanete e que a condutividade elétrica e a lixiviação de potássio podem constituir alternativas promissoras para essa finalidade. Não foram encontradas outras referências sobre o assunto, indicando a necessidade da produção de conhecimento sobre o tema.

Por outro lado, as relações entre o vigor das sementes e o desempenho das plantas em campo também não estão suficientemente esclarecidas, tanto no Brasil como no exterior. Há consenso quanto à influência do vigor sobre a emergência das plântulas e o desenvolvimento inicial das plantas, mas não se conhece perfeitamente até que pontos esses efeitos se estendem até estádios fenológicos mais avançados e afetam a produção da cultura (Carvalho, 1986; Ellis, 1992; Marcos Filho, 2005).

Nesse sentido, TeKrony e Egli (1991) destacaram que os efeitos do vigor da semente podem ser críticos para espécies colhidas durante a fase vegetativa, condição verificada em inúmeras hortaliças, pois o atraso no estabelecimento do estande afetaria a uniformidade de crescimento das plantas. Essas observações ressaltam as conclusões de Smith et al. (1973), com alface, e de Finch-Savage (1990), com repolho.

No entanto, essas observações não correspondem totalmente às efetuadas por Hanumaiah e Andrews (1973), com repolho e nabo, nem às relatadas por Ellis (1992), com cebola. Verifica-se, mesmo para hortaliças, predominância de informações ressaltando a influência do vigor das sementes durante os estádios iniciais de desenvolvimento das plantas (Piana et al., 1995), mas relatando a redução gradativa desses efeitos até desaparecer ao final do ciclo das plantas, não afetando a produção final (Rodo e Marcos Filho, 2003), principalmente quando não há diferenças no estande.

Diante do exposto, a presente pesquisa foi conduzida com o objetivo de verificar a influência do vigor de diferentes lotes de sementes de rabanete, sobre o comportamento das plantas em campo, avaliando o desenvolvimento vegetativo e a produção de raízes.

\section{MATERIAL E MÉTODOS}

O presente trabalho foi conduzido nas instalações do Laboratório de Análise de Sementes e no Campo Experimental do Departamento de Produção Vegetal, Escola Superior de Agricultura "Luiz de Queiroz", em Piraciaba/SP. Utilizaramse lotes de sementes dos cultivares Gigante Siculo e Cometa (representados por quatro e três lotes, respectivamente), mantidas em sacas em papel e armazenadas em câmara a $20^{\circ} \mathrm{C}$ e $50 \%$ de umidade relativa do ar (UR) durante todo o período experimental. $\mathrm{O}$ estudo compreendeu avaliações em laboratório e em campo.

\section{Testes de laboratório}

Foram conduzidos testes de germinação e de vigor, baseados em observações efetuadas por Carpi (2005). Em cada um dos testes, utilizaram-se cinco repetições para as sementes de 'Gigante Siculo' e sete para as de 'Cometa'.

Germinação: conduzido com repetições de 50 sementes por lote, distribuídas sobre duas folhas de papel mata-borrão colocadas no interior de caixas plásticas $(11,5 \times 11,5 \times 3,5 \mathrm{~cm})$, umedecidas com quantidade de água equivalente a 2,5 vezes 
o peso do substrato e mantidas em germinador a $20-30^{\circ} \mathrm{C}$. As avaliações foram efetuadas de acordo com as Regras para Análise de Sementes (Brasil, 1992). Foram efetuadas contagens diárias, computando-se as plântulas normais de cada repetição. Os resultados foram expressos em percentagem média de plântulas normais para cada lote, aos 14 dias após a semeadura. Considerou-se também a porcentagem de plântulas normais na data correspondente à estabelecida para a primeira contagem, aos quatro dias após a semeadura e a velocidade de germinação, calculando-se índices de acordo com Maguire (1962).

Envelhecimento acelerado com solução saturada de $\mathrm{NaCl}$ : conduzido em caixas plásticas $(11,5 \times 11,5 \times 3,5 \mathrm{~cm})$ como compartimentos individuais (mini-câmaras) adaptados para a condução de testes de envelhecimento acelerado. Distribuíramse na superfície da tela metálica, em camada única, cerca de $4,0 \mathrm{~g}$ de sementes de cada lote. Para o controle da umidade relativa do ar no interior das caixas, foram colocados $40 \mathrm{~mL}$ de solução saturada de $\mathrm{NaCl}$, proporcionando ambiente com $76 \%$ UR. Em seguida, as caixas foram mantidas em câmara do tipo "jaquetada de água" a $41^{\circ} \mathrm{C}$ durante 72 horas ou a $45^{\circ} \mathrm{C}$ durante 48 horas.

Decorrido cada período de envelhecimento, repetições de 50 sementes por tratamento foram colocadas para germinar, seguindo o mesmo procedimento descrito para o teste de germinação. A avaliação foi realizada aos quatro dias após a semeadura, computando-se a porcentagem de plântulas normais.

Deterioração controlada: inicialmente, o grau de umidade das sementes foi ajustado artificialmente até atingir 24\%, através do método da atmosfera úmida (Rossetto et al., 1995). Uma vez obtidos o grau de umidade planejado, cada amostra foi colocada em embalagem laminada de alumínio + plástico, fechada hermeticamente e mantida por cinco dias em câmara fria $\left(8-10^{\circ} \mathrm{C}\right)$, com a finalidade de uniformizar a distribuição da água no interior das sementes. Em seguida, as amostras foram mantidas em banho-maria a $45^{\circ} \mathrm{C}$, durante 24 horas; após esse período, foi determinado o grau de umidade das sementes pelo método da estufa a $105 \pm 3^{\circ} \mathrm{C}$ (Brasil, 1992) e instalado o teste de germinação, conforme descrito anteriormente. A avaliação foi efetuada aos quatro dias após a semeadura, computando-se a porcentagem média de plântulas normais para cada lote.

Condutividade elétrica: conduzido com quatro repetições de 50 sementes para cada lote e cultivar, previamente pesadas $(0.0001 \mathrm{~g})$, colocadas em copos plásticos contendo $25 \mathrm{~mL}$ de água destilada e mantidas a $25^{\circ} \mathrm{C}$ durante quatro horas. A condutividade elétrica da solução foi determinada em condutivímetro DIGIMED, modelo DM-31, e os resultados expressos em $\mathrm{mS} . \mathrm{cm}^{-1} \cdot \mathrm{g}^{-1}$ de semente.

Análise estatística: a análise da variância foi conduzida de acordo com delineamento inteiramente casualizado, separadamente para cada cultivar e teste conduzido, avaliandose os efeitos de lotes. Compararam-se as médias pelo teste de Tukey, a 5\% de probabilidade.

\section{Avaliações em campo}

Emergência de plântulas: foram utilizadas bandejas de poliestireno ("isopor") com células individuais, contendo substrato comercial (tipo Plantmax), mantidas em condições não controladas de ambiente, com irrigação periódica. Para cada lote, foram utilizadas cinco repetições de 50 sementes para o cultivar Gigante Siculo e sete para 'Cometa', colocando-se uma semente por célula. A avaliação da emergência das plântulas foi efetuada 10 dias após a semeadura, mediante a contagem de plântulas normais, avaliadas de acordo com os critérios adotados para avaliação da parte aérea de plântulas em um teste de germinação (Brasil, 1992). Os resultados foram expressos em porcentagem média de plântulas normais para cada lote.

Desenvolvimento das plantas: o ensaio de campo foi instalado após preparo convencional dos canteiros, em parcelas localizadas de acordo com o delineamento blocos ao acaso, com cinco repetições para o cultivar Gigante Siculo e sete para o 'Cometa'. A semeadura foi efetuada em 02/09/ 2004 , distribuindo-se quantidade de sementes com base nos resultados do teste de germinação, procurando-se obter estande uniforme, de 20 plantas por metro linear de sulco, para cada lote e cultivar. As parcelas foram constituídas por sete linhas de $1,0 \mathrm{~m}$ de comprimento, espaçadas $0,20 \mathrm{~m}$ entre si; a área útil de cada parcela foi representada pelas cinco linhas centrais, de modo que compreendia $5 \mathrm{~m}^{2}$.

Foram dispensados às plantas os tratos culturais recomendados para a cultura do rabanete (Filgueira, 2000). Por exemplo, a adubação não foi necessária porque o solo apresentava níveis adequados de nutrientes; as irrigações foram diárias. A colheita de raízes foi realizada aos 30 dias após a semeadura.

Aos 11, 18, 23 e 30 dias após a semeadura, foram coletadas amostras de 10 plantas por parcela e conduzidas as seguintes determinações, obtendo-se valores médios por lote e cultivar:

a) altura das plantas: avaliada em centímetros, mediante a tomada da medida entre o colo e o ápice da folha com maiores dimensões; 
b) massa da matéria seca: aos 11 dias foi determinada apenas a massa da matéria seca da parte aérea das plantas; nas épocas seguintes avaliou-se, também, a das raízes; para tanto, a parte aérea e raízes foram separadas, embaladas em sacos de papel e submetidas à secagem. Esta foi conduzida em estufa a $70^{\circ} \mathrm{C}$, até peso constante, seguida por pesagem em balança analítica (precisão $0,0001 \mathrm{~g}$ );

c) diâmetro na região do colo das plantas: medido com o auxílio de paquímetro e obtenção de dados em centímetros;

d) número médio de folhas: obtido mediante a contagem do número de folhas das plantas amostradas.

Produção de raízes: A colheita de raízes e avaliação da produção final foi efetuada aos 30 dias após a semeadura, com base em avaliações preliminares; para tanto, arrancaramse periodicamente (a partir dos 21 dias) plantas de linhas bordadura para monitoramento do final do ciclo e verificação do estádio de desenvolvimento das raízes, pois não é possível identificar a maturidade das raízes apenas com o exame visual da parte aérea das plantas. Assim, quando as raízes atingiram o tamanho desejado e apresentavam as características típicas de cada um dos cultivares, as plantas de cada parcela útil foram arrancadas, colocadas em sacos plásticos e conduzidas ao laboratório.

Em seguida, procedeu-se ao descarte da parte aérea, as raízes foram lavadas e pesadas $(0,1 \mathrm{~g})$; calculou-se o peso médio das raízes de cada lote e cultivar e os valores foram convertidos para t.ha ${ }^{-1}$.

Análise estatística: realizada de acordo com delineamento blocos ao acaso, testando-se os efeitos de lotes separadamente para cada lote e cultivar. As médias foram comparadas pelo método de Tukey, a 5\% de probabilidade.

\section{RESULTADOS E DISCUSSÃO}

A germinação dos lotes das duas cultivares utilizados nesta pesquisa era superior à mínima estabelecida $(\geq 80 \%)$ para a comercialização de sementes de rabanete. As diferenças no potencial fisiológico das sementes de cada cultivar eram estreitas e não foram detectadas pelo teste de germinação (Tabela 1).

Verificou-se que os lotes das duas cultivares não diferiram quanto à porcentagem de germinação, tanto na primeira contagem como no valor total, o mesmo ocorrendo para a velocidade. Essas observações confirmam a menor sensibilidade de parâmetros relacionados à germinação determinada em laboratório, para identificar diferenças no desempenho das sementes, freqüentemente destacada na literatura. Mesmo assim, verificou-se que os valores médios da primeira contagem e do índice de velocidade de germinação referentes ao lote 4 de 'Gigante Siculo' foram numericamente inferiores aos obtidos para os demais lotes dessa cultivar.

Os testes de deterioração controlada e de condutividade elétrica identificaram o desempenho significativamente inferior do lote 4 de 'Gigante Siculo', enquanto o teste de envelhecimento acelerado com solução salina não diferenciou os lotes dessa cultivar.

Por outro lado, os testes de condutividade elétrica e de

TABELA 1. Valores médios referentes a porcentagem total (G), primeira contagem (PCG) e velocidade de germinação (VG), envelhecimento acelerado com solução salina (EASS), deterioração controlada (DC), condutividade elétrica (CE), emergência de plântulas (EP) e respectivos coeficientes de variação, em diferentes lotes de sementes de rabanete, cultivares Gigante Siculo e Cometa. Piracicaba, USP/ESALQ, 2005.

\begin{tabular}{|c|c|c|c|c|c|c|c|c|c|}
\hline Cultivar & Lotes & $\begin{array}{c}\mathrm{G} \\
(\%)\end{array}$ & $\begin{array}{c}\text { PCG } \\
(\%)\end{array}$ & $\begin{array}{c}\mathrm{VG} \\
\text { (índice) }\end{array}$ & $\begin{array}{c}\text { EASS 41/72 } \\
(\%)\end{array}$ & $\begin{array}{c}\text { EASS } 45 / 48 \\
(\%)\end{array}$ & $\begin{array}{l}\mathrm{DC} \\
(\%)\end{array}$ & $\begin{array}{c}\text { CE } \\
\left(\mu \text { S.cm }{ }^{-1} \cdot \mathrm{g}^{-1}\right)\end{array}$ & EP (\%) \\
\hline Gigante & 1 & $95 \mathrm{~A}$ & $93 \mathrm{~A}$ & $18,6 \mathrm{~A}$ & $97 \mathrm{~A}$ & $94 \mathrm{~A}$ & $91 \mathrm{~A}$ & $191,79 \mathrm{~A}$ & $94 \mathrm{~A}$ \\
\hline \multirow{5}{*}{ Siculo } & 2 & $96 \mathrm{~A}$ & $94 \mathrm{~A}$ & $18,5 \mathrm{~A}$ & $93 \mathrm{~A}$ & $92 \mathrm{~A}$ & $90 \mathrm{~A}$ & $212,47 \mathrm{~A}$ & $93 \mathrm{~A}$ \\
\hline & 3 & $97 \mathrm{~A}$ & $95 \mathrm{~A}$ & $19,7 \mathrm{~A}$ & $92 \mathrm{~A}$ & $92 \mathrm{~A}$ & $92 \mathrm{~A}$ & $207,58 \mathrm{~A}$ & $94 \mathrm{~A}$ \\
\hline & 4 & $95 \mathrm{~A}$ & $88 \mathrm{~A}$ & $18,0 \mathrm{~A}$ & $92 \mathrm{~A}$ & $89 \mathrm{~A}$ & $76 \mathrm{~B}$ & $269,42 \mathrm{~B}$ & $94 \mathrm{~A}$ \\
\hline & C.V. $(\%)$ & $\overline{10,3}$ & $10, \overline{3}$ & $\overline{0}$ & -7 & $-5 \overline{1}$ & $\overline{3}, \overline{4}$ & $\overline{12,6}$ & $\overline{6}, \overline{7}$ \\
\hline & Lotes & $\begin{array}{c}G \\
(\%)\end{array}$ & $\begin{array}{c}\text { PCG } \\
(\%)\end{array}$ & $\begin{array}{c}\mathrm{VG} \\
\text { (índice) }\end{array}$ & $\begin{array}{c}\text { EASS 41/72 } \\
(\%)\end{array}$ & $\begin{array}{c}\text { EASS 45/48 } \\
(\%)\end{array}$ & $\begin{array}{l}\mathrm{DC} \\
(\%)\end{array}$ & $\begin{array}{c}\mathrm{CE} \\
\left(\mu \mathrm{S} \cdot \mathrm{cm}^{-1} \cdot \mathrm{g}^{-1}\right)\end{array}$ & EP (\%) \\
\hline \multirow[t]{4}{*}{ Cometa } & 5 & $94 \mathrm{~A}$ & $93 \mathrm{~A}$ & $19,0 \mathrm{~A}$ & $90 \mathrm{~A}$ & $89 \mathrm{~B}$ & $84 \mathrm{~A}$ & $193,51 \mathrm{~B}$ & $87 \mathrm{~B}$ \\
\hline & 6 & $94 \mathrm{~A}$ & $92 \mathrm{~A}$ & $18,4 \mathrm{~A}$ & $96 \mathrm{~A}$ & $87 \mathrm{~B}$ & $86 \mathrm{~A}$ & $202,35 \mathrm{~B}$ & $93 \mathrm{AB}$ \\
\hline & 7 & $97 \mathrm{~A}$ & $94 \mathrm{~A}$ & $18,4 \mathrm{~A}$ & $94 \mathrm{~A}$ & $95 \mathrm{~A}$ & $84 \mathrm{~A}$ & $182,98 \mathrm{~A}$ & $94 \mathrm{~A}$ \\
\hline & C.V. $(\%)$ & $-\overline{5,8}$ & $\overline{5}, 2$ & $\overline{6}, \overline{4}$ & $\overline{6,4}$ & $5, \overline{2}$ & $\overline{6}, \overline{3}$ & $9, \overline{1}$ & $\overline{6}, \overline{7}$ \\
\hline
\end{tabular}

(*) Comparação de médias dentro de cada coluna (Teste de Tukey, $5 \%$ de probabilidade) 
envelhecimento acelerado com solução salina $\left(45^{\circ} \mathrm{C} / 48 \mathrm{~h}\right)$ acusaram a superioridade significativa do potencial fisiológico das sementes do lote 7 , em relação ao lote 5 , observação comparável à emergência das plântulas.

Não havendo referências anteriores com detalhamento suficiente para a avaliação do vigor de sementes de rabanete para a confrontação dos resultados desta pesquisa, a alternativa é ressaltar que a eficiência do teste de condutividade elétrica foi relatada anteriormente para outras hortaliças, como cenoura (Andrade et al., 1995), pimentão (Panobianco e Marcos Filho, 1998), brócolos (Mello et al., 1999), dentre várias outras.

A sensibilidade do teste de deterioração controlada também tem sido amplamente documentada na literatura. No presente trabalho, houve confirmação de observações efetuadas por vários pesquisadores, dentre os quais Pandey et al. (1990), com melão e pepino; Powell (1995), mencionando várias espécies; Mendonça et al. (2000), com brócolos; Panobianco e Marcos Filho (2001), com tomate.

Paralelamente, o teste de envelhecimento acelerado com solução saturada de $\mathrm{NaCl}$ detectou diferenças entre os lotes de 'Cometa', proporcionando informações comparáveis às destacadas por Rodo et al. (2000), com cenoura, Bhéring et al. (2000), com pepino, e Martins at al. (2002), com brócolos. Conseqüentemente, os testes de condutividade elétrica, deterioração controlada e envelhecimento acelerado com solução salina merecem atenção e podem ser considerados promissores para a avaliação do potencial fisiológico de sementes de rabanete. Há necessidade, porém, da continuidade de estudos dessa natureza para assegurar a consistência desses procedimentos.

De modo geral, as plantas de 'Gigante Siculo' não exibiram variações acentuadas em seu desempenho, sob a influência do vigor dos lotes de sementes utilizados (Tabelas 2 e 3). Aos 11, aos 18 e aos 23 dias após a semeadura, notouse que as médias referentes à altura e massa da matéria seca de plantas originadas do lote 4 foram inferiores às dos demais lotes, mas essa diferença foi estatisticamente significativa apenas aos 18 dias.

O exame das Tabelas 4 e 5, referentes a 'Cometa', permite verificar que aos 23 e aos 30 dias após a semeadura, as plantas provenientes do lote 7 se destacaram quanto à altura, massa de matéria seca e diâmetro do colo.

A inferioridade do desempenho das plantas originadas do lote 4 de 'Gigante Siculo' e a superioridade proporcionada pelo lote $7 \mathrm{de}$ 'Cometa' correspondem a informações provenientes do teste de condutividade elétrica conduzido com sementes das duas cultivares, de deterioração controlada, para as sementes de 'Gigante Siculo', e de envelhecimento acelerado com solução saturada de sal para as de 'Cometa'. No entanto, a possível relação entre os resultados obtidos em laboratório e o desempenho das plantas em campo não se estendeu até a produção final, mesmo nas plantas de 'Cometa', em que características da planta foram afetadas praticamente até o final do ciclo.

É provável que as variações do vigor das sementes não tenham sido suficientemente amplas para se refletir em todo

TABELA 2. Valores médios referentes a altura de plantas - AP $(\mathrm{cm})$, diâmetro na região do colo - $\mathrm{DRC}(\mathrm{cm})$, número de folhas por planta - NFP, massa de matéria seca-MMS (g) e respectivos coeficientes de variação, obtidos aos 11 e aos 18 dias após a semeadura de quatro lotes de sementes de rabanete, cultivar Gigante Siculo. Piracicaba, USP/ESALQ, 2005.

\begin{tabular}{|c|c|c|c|c|c|}
\hline Lotes & $\begin{array}{l}\text { AP - } 11 \text { dias } \\
(\mathrm{cm})\end{array}$ & $\begin{array}{c}\text { DRC - } 11 \text { dias } \\
(\mathrm{cm})\end{array}$ & \multicolumn{2}{|c|}{ NFP - 11 dias } & $\begin{array}{c}\text { MMS parte aérea - } 11 \\
\text { dias }(\mathrm{g})\end{array}$ \\
\hline 1 & $2,8 \mathrm{~A}$ & $0,15 \mathrm{~A}$ & \multicolumn{2}{|c|}{$1,3 \mathrm{~A}$} & $0,0221 \mathrm{~A}$ \\
\hline 2 & $3,0 \mathrm{~A}$ & $0,16 \mathrm{~A}$ & \multicolumn{2}{|c|}{$1,2 \mathrm{~A}$} & $0,0241 \mathrm{~A}$ \\
\hline 3 & $3,3 \mathrm{~A}$ & $0,14 \mathrm{~A}$ & \multicolumn{2}{|c|}{$1,3 \mathrm{~A}$} & $0,0232 \mathrm{~A}$ \\
\hline$\underline{4}$ & $2,6 \mathrm{~A}$ & $0,15 \mathrm{~A}$ & \multicolumn{2}{|c|}{$1,1 \mathrm{~A}$} & $0,0192 \mathrm{~A}$ \\
\hline C.V. $(\%$ & 12,7 & 13,0 & \multicolumn{2}{|c|}{$\overline{15,4}$} & $12, \overline{6}$ \\
\hline Lotes & $\begin{array}{c}\text { AP - } 18 \text { dias } \\
(\mathrm{cm})\end{array}$ & $\begin{array}{c}\mathrm{DRC}-18 \text { dias } \\
(\mathrm{cm})\end{array}$ & NFP 18 dias & $\begin{array}{l}\text { MMS raiz - } \\
18 \text { dias }(\mathrm{g})\end{array}$ & $\begin{array}{c}\text { MMS parte aérea } 18 \\
\text { dias }(\mathrm{g})\end{array}$ \\
\hline 1 & $8,1 \mathrm{AB}$ & $0,31 \mathrm{~A}$ & $3,7 \mathrm{~A}$ & $0,0664 \mathrm{~A}$ & $0,168 \mathrm{AB}$ \\
\hline 2 & $8,1 \mathrm{AB}$ & $0,30 \mathrm{~A}$ & $3,9 \mathrm{~A}$ & $0,0652 \mathrm{~A}$ & $0,159 \mathrm{AB}$ \\
\hline 3 & $8,4 \mathrm{~A}$ & $0,31 \mathrm{~A}$ & $3,9 \mathrm{~A}$ & $0,0650 \mathrm{~A}$ & $0,174 \mathrm{~A}$ \\
\hline$\underline{4}$ & $7,2 \underline{B}$ & $0,32 \underline{A}$ & $\underline{3}, \underline{7} \mathrm{~A}$ & $0,0643 \mathrm{~A}$ & $0,13 \underline{B} \underline{B}$ \\
\hline C.V. $(\%$ & 8,3 & $\overline{7}, \overline{7}$ & $7, \overline{7}$ & 13,5 & 12,4 \\
\hline
\end{tabular}

(*) Comparação de médias dentro de cada coluna (Teste de Tukey, 5\% de probabilidade) 
TABELA 3. Valores médios referentes a altura de plantas - AP $(\mathrm{cm})$, diâmetro na região do colo - DRC (cm), número de folhas por planta - NFP, massa de matéria seca-MMS (g), obtidos aos 23 e aos 30 dias após a semeadura, produção de raízes de quatro lotes de sementes de rabanete, cultivar Gigante Siculo e respectivos coeficientes de variação. Piracicaba, USP/ ESALQ, 2005.

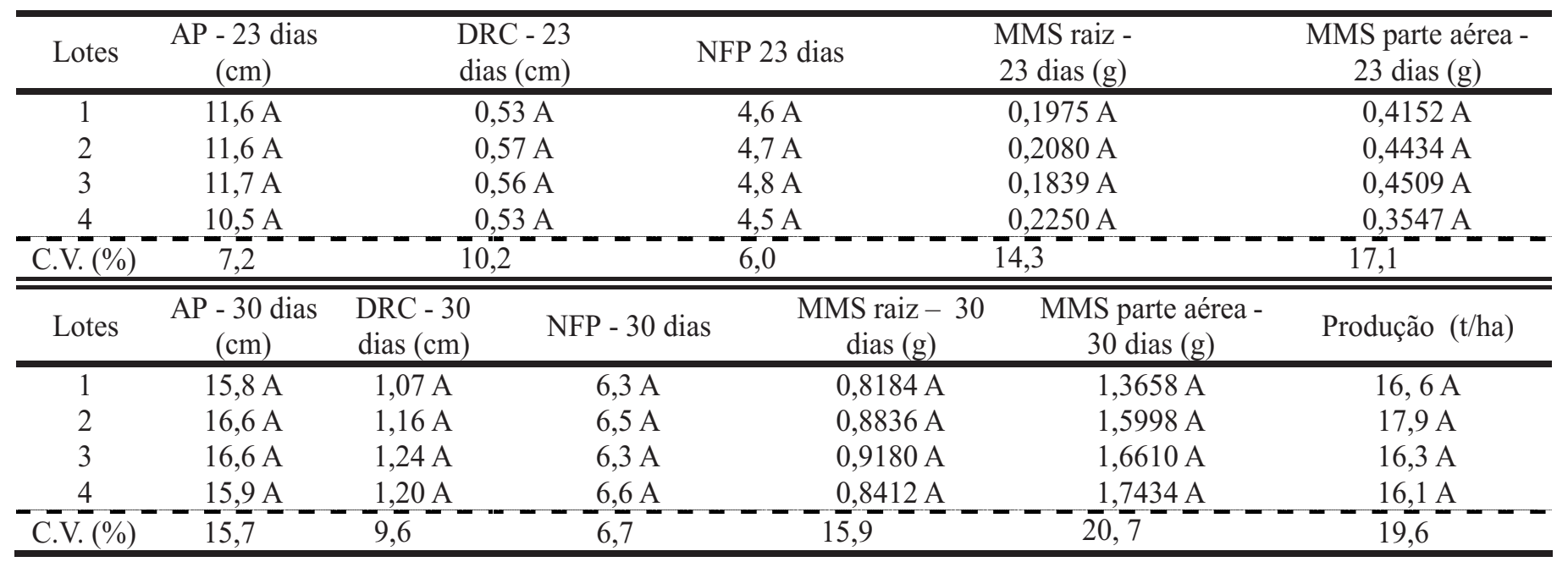

(*) Comparação de médias dentro de cada coluna (Teste de Tukey, 5\% de probabilidade)

TABELA4. Valores médios referentes a altura de plantas - AP $(\mathrm{cm})$, diâmetro na região do colo - DRC (cm), número de folhas por planta - NFP, massa de matéria seca - MMS (g)e respectivos coeficientes de variação, obtidos aos 11 e aos 18 dias após a semeadura de quatro lotes de sementes de rabanete, cultivar Cometa. Piracicaba, USP/ESALQ, 2005.

\begin{tabular}{|c|c|c|c|c|c|}
\hline Lotes & \multicolumn{3}{|c|}{ DRC - 11 dias $(\mathrm{cm})$} & NFP - 11 dias & MMS parte aérea - 11 dias (g) \\
\hline 5 & $2,3 \mathrm{AB}$ & $0,14 \mathrm{AB}$ & & $1,0 \mathrm{~A}$ & $0,0163 \mathrm{~A}$ \\
\hline 6 & $2,7 \mathrm{~A}$ & $0,16 \mathrm{~A}$ & & $1,0 \mathrm{~A}$ & $0,0200 \mathrm{~A}$ \\
\hline 7 & $2,0 \mathrm{~B}$ & $0,13 \mathrm{~B}$ & & $0,9 \mathrm{~A}$ & $0,0155 \mathrm{~A}$ \\
\hline$\overline{\mathrm{C}} \cdot \overline{\mathrm{V}} \cdot(\overline{\%})$ & $\overline{9,5}$ & 10,8 & & $1 \overline{7}, \overline{7}$ & $1 \overline{2}, \overline{7}$ \\
\hline Lotes & AP - 18 dias $(\mathrm{cm})$ & DRC - 18 dias $(\mathrm{cm})$ & NFP 18 dias & MMS raiz - 18 dias $(\mathrm{g})$ & MMS parte aérea 18 dias $(\mathrm{g})$ \\
\hline 5 & $7,1 \mathrm{~A}$ & $0,33 \mathrm{~A}$ & $3,7 \mathrm{~A}$ & $0,0786 \mathrm{~A}$ & $0,1133 \mathrm{~A}$ \\
\hline 6 & $7,0 \mathrm{~A}$ & $0,32 \mathrm{~A}$ & $3,7 \mathrm{~A}$ & $0,0777 \mathrm{~A}$ & $0,1121 \mathrm{~A}$ \\
\hline 7 & $7,9 \mathrm{~A}$ & $0,34 \mathrm{~A}$ & $3,8 \mathrm{~A}$ & $0,0567 \mathrm{~A}$ & $0,1395 \mathrm{~A}$ \\
\hline $\bar{C} \cdot \bar{V} .(\overline{\%})$ & $\overline{1} 1,4$ & $\overline{8}, \overline{3}-$ & $6, \overline{3}$ & 16,2 & $1 \overline{6}, \overline{1}$ \\
\hline
\end{tabular}

(*) Comparação de médias dentro de cada coluna (Teste de Tukey, $5 \%$ de probabilidade)

o desenvolvimento das plantas; porém, conforme enfatizou Ellis (1992), o vigor das sementes pode proporcionar um impulso inicial ao crescimento das plântulas, mas a extensão desses efeitos não está completamente esclarecida. Paralelamente, é provável que as diferenças no potencial fisiológico das sementes, identificado em laboratório, não tenham sido amplas ao ponto de afetar a produção final. De acordo com TeKrony e Egli (1991), desde que as plantas tenham ultrapassado um nível mínimo de desenvolvimento, o vigor das sementes não afetaria a produção.
Carvalho (1986) enfatizou que os efeitos do vigor das sementes sobre o desempenho das plantas podem ser evidentes no início do desenvolvimento, mas são reduzidos à medida que os estádios fenológicos se sucedem. Essa observação foi confirmada por vários autores, dentre os quais Rodo e Marcos Filho (2003), trabalhando com cebola.

Desta maneira, os resultados aqui obtidos permitem enfatizar que o uso de sementes vigorosas é justificável para assegurar o estabelecimento adequado do estande, mesmo que não haja resposta consistente em termos de produção final das plantas. 
TABELA 5. Valores médios referentes a altura de plantas - AP $(\mathrm{cm})$, diâmetro na região do colo - DRC (cm), número de folhas por planta - NFP, massa de matéria seca-MMS (g), obtidos aos 23 e aos 30 dias após a semeadura, e produção de raízes de quatro lotes de sementes de rabanete, cultivar Cometa, e respectivos coeficientes de variação. Piracicaba, USP/ESALQ, 2005 .

\begin{tabular}{|c|c|c|c|c|c|c|}
\hline Lotes & $\begin{array}{c}\text { AP - } 23 \\
\text { dias }(\mathrm{cm})\end{array}$ & $\begin{array}{l}\text { DRC - } 23 \\
\text { dias }(\mathrm{cm})\end{array}$ & \multicolumn{2}{|c|}{ NFP 23 dias } & MMS raiz - 23 dias (g) & $\begin{array}{l}\text { MMS parte aérea - } \\
23 \text { dias }(\mathrm{g})\end{array}$ \\
\hline 5 & $9,8 \mathrm{AB}$ & $0,46 \mathrm{~B}$ & \multicolumn{2}{|l|}{$4,5 \mathrm{~A}$} & $0,2203 \mathrm{~A}$ & $0,2402 \mathrm{~B}$ \\
\hline 6 & $8,9 \mathrm{~B}$ & $0,46 \mathrm{~B}$ & \multicolumn{2}{|l|}{$4,5 \mathrm{~A}$} & $0,2302 \mathrm{~A}$ & $0,2504 \mathrm{~B}$ \\
\hline 7 & $11,9 \mathrm{~A}$ & $0,52 \mathrm{~A}$ & $4,8 \mathrm{~A}$ & \multicolumn{2}{|r|}{$0,2105 \mathrm{~A}$} & $0,3811 \mathrm{~A}$ \\
\hline $\bar{C} \cdot \bar{V} .(\overline{\%})$ & & $9, \overline{5}$ & \multicolumn{2}{|l|}{$\overline{7}, \overline{8}$} & $\overline{12}, \overline{9}$ & $\overline{1} 4, \overline{4}---$ \\
\hline Lotes & $\begin{array}{c}\text { AP - 30 } \\
\text { dias }(\mathrm{cm})\end{array}$ & $\begin{array}{l}\text { DRC - 30 } \\
\text { dias }(\mathrm{cm})\end{array}$ & $\begin{array}{c}\text { NFP - } 30 \\
\text { dias }\end{array}$ & $\begin{array}{c}\text { MMS raiz- } \\
30 \text { dias }(\mathrm{g})\end{array}$ & $\begin{array}{c}\text { MMS parte aérea - } \\
30 \text { dias }(\mathrm{g})\end{array}$ & Produção (t/ha) \\
\hline 5 & $11,8 \mathrm{~B}$ & $0,84 \mathrm{~B}$ & $5,7 \mathrm{~B}$ & $0,5392 \mathrm{~A}$ & $0,7698 \mathrm{~B}$ & $12,8 \mathrm{~A}$ \\
\hline 6 & $12,4 \mathrm{~B}$ & $0,88 \mathrm{~B}$ & $6,0 \mathrm{AB}$ & $0,5904 \mathrm{~A}$ & $0,8463 \mathrm{~B}$ & $15,0 \mathrm{~A}$ \\
\hline 7 & $16,5 \mathrm{~A}$ & $1,12 \mathrm{~A}$ & $6,5 \mathrm{~A}$ & $0,7431 \mathrm{~A}$ & $1,3691 \mathrm{~A}$ & $12,7 \mathrm{~A}$ \\
\hline C.V. & 15,2 & & $8, \overline{9}$ & 15,0 & $\overline{13}, \overline{2}$ & $1 \overline{6}, 0$ \\
\hline
\end{tabular}

(*) Comparação de médias dentro de cada coluna (Teste de Tukey, $5 \%$ de probabilidade)

\section{CONCLUSÃO}

O vigor de sementes de rabanete pode ser responsável por um impulso ao desenvolvimento inicial das plantas, mas esse efeito não persiste até a produção final.

\section{REFERÊNCIAS}

ANDRADE, R.N.; SANTOS, D.S.B.; SANTOS FILHO, B.G.; MELLO, V.D.C. Correlação entre testes de vigor em sementes de cenoura armazenadas por diferentes períodos. Pesquisa Agropecuária Gaúcha, Porto Alegre, v.1, n.2, p.153-162, 1995.

BHÉRING, M.C.; DIAS, D.C.F.S.; GOMES, J.M.; BARROS, D.I. Métodos para avaliação do vigor de sementes de pepino. Revista Brasileira de Sementes, Londrina, v.22, n.2, p.171-175, 2000.

BRASIL. Ministério da Agricultura e Reforma Agrária. Regras para análise de sementes. Brasília: SNDAV/DNDV/CLAV 1992. $365 \mathrm{p}$.

CARPI, V.A.F. Avaliação do potencial fisiológico de sementes de rabanete. 2005. 77f. Dissertação (Mestrado em Agronomia, Área de Concentração Fitotecnia) - Escola Superior de Agricultura “Luiz de Queiroz”, Universidade de São Paulo, Piracicaba, 2005.

CARVALHO, N.M. Vigor de sementes. In: MARCOS FILHO, J.; CICERO, S.M.; SILVA, W.R. (Ed.) Atualização em produção de sementes. Campinas: Fundação Cargill, 1986. p.207-223.

DELOUCHE, J.C.; BASKIN, C.C. Accelerated aging techniques for predicting the relative storability of seed lots. Seed Science and Technology, Zürich, v.1, n.2, p.427-452, 1973.

ELLIS, R.H. Seed and seedling vigor in relation to growth and yield. Plant Growth Regulation, v.11, n.1, p. 249-255, 1992.

FILGUEIRA, F.A.R. Novo manual de olericultura: agrotecnologia moderna na produção e comercialização de hortaliças. Viçosa: UFV, 2000. 402p.

FINCH-SAVAGE, N.E.; McKEE, J.M.T. The influence of seed quality and pregermination treatment on cauliflower and cabbage transplant production and field growth. Annals of Applied Biology, v.116, n.1, p.365-369, 1990.

HAMPTON, J.G.; TeKRONY, D.M. Handbook of vigor test methods. Zürich: ISTA, 1995. 117p.

HANUMAIAH, L.; ANDREWS, H. Effects of seed size in cabbage and turnip on performance of seeds, seedlings and plants. Proceedings of the Association of Official Seed Analysts, v.63, p.117-125, 1973.

MAGUIRE, J.D. Speed of germination aid in selection and evaluation for seedling emergence and vigor. Crop Science, Madison, v.2, n.2, p.176-177, 1962.

MARCOS FILHO, J. Fisiologia de sementes de plantas cultivadas. Piracicaba: FEALQ, 2005. 495p.

MARTINS, C.C.; MARTINELLI-SENEME, A.; CASTRO, M.M.; NAKAGAWA, J.; CAVARIANI, C. Comparação entre métodos para avaliação do vigor de lotes de sementes de couve-brócolos. Revista Brasileira de Sementes, Londrina, v.24, n.2, p.96-101, 2002.

MELLO, S.C.; SPINOLA, M.C.M.; MINAMI, K. Métodos de avaliação da qualidade fisiológica de sementes de brócolos. Scientia Agricola, Piracicaba, v.56, n.4, p.1151-1155, 1999.

MENDONÇA, E.A.F.; RAMOS, N.P.; FESSEL, S.A.; SADER, R. Teste de deterioração controlada em sementes de brocoli. Revista Brasileira de Sementes, Londrina, v.22, n.2, p.280-287, 2000.

PANDEY, P.K.; GOYAL, R.D.; PRAKASH, V.; KATIVAR, R.P.; SINGH, C.B. Association between laboratory vigour tests and field emergence in cucurbits. Seed Research, Nova Delhi, v.18, n.1, p.40-43, 1990.

PANOBIANCO, M.; MARCOS FILHO, J. Comparação entre 
métodos para avaliação da qualidade fisiológica de sementes de pimentão. Revista Brasileira de Sementes, Brasília, v.20, n.2, p.306-310, 1998 .

PANOBIANCO, M.; MARCOS FILHO, J. Evaluation of the physiological potential of tomato seeds by germination and vigor tests. Seed Technology, Lexington, v.23, n.2, p.151-161, 2001.

PIANA, Z.; TILLMANN, M.A.A.; MINAMI, K. Avaliação da qualidade fisiológica de sementes de cebola e sua relação com a formação de mudas vigorosas. Revista Brasileira de Sementes, Brasília, v.17, n.2, p.149-153, 1995.

POWELL, A.A. The controlled deterioration test. In: INTERNATIONAL SEED TESTING ASSOCIATION. Seed vigour testing seminar. Zürich, 1995. p.73-87.

RODO, M.A.B.; MARCOS FILHO, J. Onion seed vigor in relation to plant growth and yield. Horticultura Brasileira, Brasília, v.21, n. 2, p. $220-226,2003$.
RODO, A.B.; PANOBIANCO, M.; MARCOS FILHO, J.; Metodologia alternativa do teste de envelhecimento acelerado para sementes de cenoura. Scientia Agricola, Piracicaba, v.57, n.2, p.289-292, 2000.

ROSSETO, C.A.V.; FERNANDEZ, E.M.; MARCOS FILHO, J. Metodologias de ajuste do grau de umidade e comportamento das sementes de soja no teste de germinação. Revista Brasileira de Sementes, Brasília, v.17, n.2, p.171-178, 1995.

SMITH, O.E.; WELSH, N.C.; McCOY, O.D. Studies on lettuce seed quality. II. Relationship of seed vigor to emergence, seedling weight and yield. Journal of American Society of Horticulture Science, v.98, n.3, p.552-556, 1973.

TeKRONY, D.M.; EGLI, D.B. Relationship of seed vigor to crop yield. Crop Science, Madison, v.31, n.3, p.816-822, 1991.

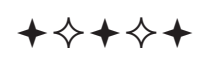

